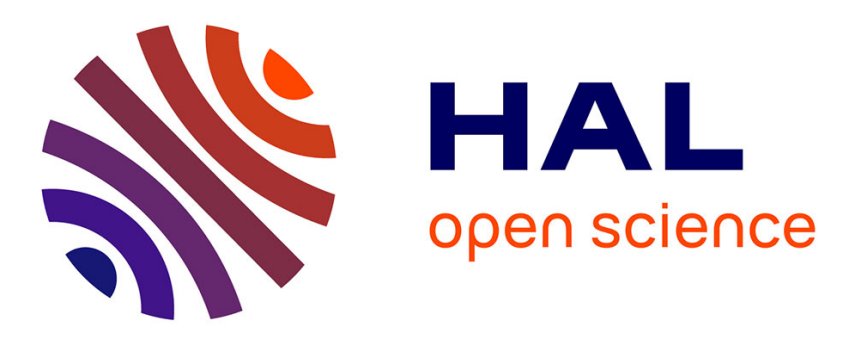

\title{
Bimorph hybrid fluid diaphragm device for vibration energy harvesting
}

\author{
Florian Huet, Fabien Formosa, Adrien Badel
}

\section{To cite this version:}

Florian Huet, Fabien Formosa, Adrien Badel. Bimorph hybrid fluid diaphragm device for vibration energy harvesting. 2016 11th France-Japan \& 9th Europe-Asia Congress on Mechatronics (MECATRONICS) /17th Internationall Conference on Research and Education in Mechatronics (REM), Jun 2016, Compiègne, France. pp.327-330. hal-02042747

\section{HAL Id: hal-02042747 https://hal.science/hal-02042747}

Submitted on 26 Feb 2019

HAL is a multi-disciplinary open access archive for the deposit and dissemination of scientific research documents, whether they are published or not. The documents may come from teaching and research institutions in France or abroad, or from public or private research centers.
L'archive ouverte pluridisciplinaire HAL, est destinée au dépôt et à la diffusion de documents scientifiques de niveau recherche, publiés ou non, émanant des établissements d'enseignement et de recherche français ou étrangers, des laboratoires publics ou privés. 


\title{
Bimorph hybrid fluid diaphragm device for vibration energy harvesting
}

\author{
Florian Huet, Fabien Formosa and Adrien Badel \\ Univ. Savoie Mont Blanc - SYMME Laboratory, \\ Annecy, F-74000 FRANCE \\ Email: Florian.Huet@univ-smb.fr
}

\begin{abstract}
A low resonant frequency piezoelectric energy harvesting using a hybrid fluid diaphragm (HFD) is presented. This paper describes the design, fabrication and characterization of such a device for harvesting energy from vibrations. The PHFD consists in an incompressible fluid confined between two thin piezoelectric membranes. The output voltage and power of the P(VDF-TrFE) HFD are studied based on experimental and simulation results. This device resonates at $164 \mathrm{~Hz}$ for low acceleration $\left(10 \mathrm{~m} / \mathrm{s}^{2}\right)$. The simulations showed the power production of about $6 \mu \mathrm{W}$ with a power density of $78.98 \mu \mathrm{W} / \mathrm{cm}^{3}$ of electroactive material volume.
\end{abstract}

Keywords-Vibration energy harvesting; Piezoelectric membrane; Fluid-structure interaction; Linear generator

\section{INTRODUCTION}

An increasing interest in wireless sensors networks has been growing up over recent years. The implementation of communicating sensors networks in industrial application, transport or buildings offers possible improvements: productivity gains, reliability and energy performance are feasible by the exploitation of the extensive collected information (temperature, humidity, electric consumption...). With the rapid advancement of low-power wireless sensor nodes, energy harvesting has attracted worldwide research interests [1].

Vibration energy harvesting (VEH) generators have been proposed using three main transduction principles: piezoelectric, electromagnetic and electrostatic [2], [3]. In order to extract the maximum power from the environment, the resonant frequency of a linear harvesting device has to match the dominant frequency of the excitation. Indeed frequencies of ambient available vibration sources are relatively low (typically less than $200 \mathrm{~Hz}$ ) [4]. As a result, many VEH piezoelectric energy harvesters of centimeter scale have been demonstrated to operate at low frequencies.

PVDF (or similar materials P(VDF-TrFE, loaded PVDF, ...) is chosen as piezoelectric transducer [5]-[8] in many $\mathrm{VEH}$. The flexibility of this material is a major advantage for low frequency application, but its intrinsic performance is lower than PZT. The reached power density (considering the volume of piezoelectric material) from the studied literature shows a range from $0.15 \mu \mathrm{W} / \mathrm{cm}^{3}$ [5] to $195.12 \mu \mathrm{W} / \mathrm{cm}^{3}$ [7].

This paper reports the modelling, fabrication and testing of a new piezoelectric fluid-membrane structure for vibration energy harvesting. Compared to classical cantilever architectures, this approach takes advantage of the mechanical strain of circular diaphragms. However, when miniaturized, they present high resonant frequency [9] and it hinders their direct use. The concept of piezoelectric hybrid fluid diaphragm (PHFD) consists in an incompressible fluid confined between two thin piezoelectric membranes. It allows the realization of low resonant frequency system as the fluid is used as an inerttial mass. Moreover, pressure fluctuation harvesting [10] can be especially targeted.

\section{INERTIAL PIEZOELECTRIC HFD GENERATOR}

\section{A. Bimorph piezoelectric HFD concept}

We propose here, an innovative architecture for vibration energy harvesters. Fig.1 describes the geometry as well as the main geometrical parameters of the structure. The incompressible fluid is used as an inertial mass which allows a drastic reduction of the resonant frequency to effectively harvest ambient vibrations. The height of the structure can be easily tunned to provide more or less inertia effect. In a previously published work, the mechanical behavior of a HFD was presented [11]. As an example of the frequency reduction, the use of glycerin allowed the resonant frequency of Kapton ${ }^{\circledR}$ membranes $(R=10 \mathrm{~mm}, H=20 \mathrm{~mm}$ and $h=100 \mu \mathrm{m})$ to decrease from $1200 \mathrm{~Hz}$ to $180 \mathrm{~Hz}$.

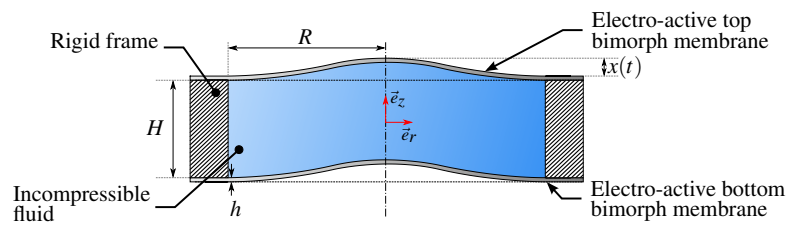

Figure 1: Architecture of the piezoelectric HFD

The circular diaphragms are made from thin P(VDF-TrFE) bimorph film. The film is composed of two piezoelectric material layer with structured electrodes. Table I defines the geometrical parameters and material properties of the system.

\section{B. Theoretical model}

A comprehensive theoretical model was proposed in [11]. Based on the Ritz method, approximate solutions for the fluid and the mechanicals diaphragms behaviours are set. This prior model is modified and extended here. Because, the final investigated dynamic behavior of the HFD in the vicinity of its first resonant frequency is notably lower than the first 
Table I: Main parameters of the PHFD

Diaphragm properties (P(VDF-TrFE))

\begin{tabular}{lc|lc}
\hline Radius $(\mathrm{m})$ & $R$ & Thickness $(\mathrm{m})$ & $h$ \\
Young modulus $(\mathrm{Pa})$ & $E$ & Poisson coefficient & $v$ \\
Piezoelectric coefficient $(\mathrm{C} / \mathrm{N})$ & $d_{31}$ & Relative permittivity & $\varepsilon_{33}$ \\
\hline
\end{tabular}

Fluid Properties (Glycerin)

\begin{tabular}{ll|ll}
\hline Height $(\mathrm{m})$ & $H$ & Density $\left(\mathrm{kg} / \mathrm{m}^{3}\right)$ & $\rho_{f}$ \\
\hline
\end{tabular}

natural frequency of a single diaphragm, it is thought that a simple static behavior. This approximation allows to propose an approached solution simplifying the model. Moreover, the electromechanical nature of the piezoelectric membranes is added in the model through the usual linear piezoelectric constitutive relations. The modelling strategy is developed using the following assumptions:

- Ideal geometry and homogeneous material properties

- Incompressible and inviscid fluid

- Elastic cylindrical diaphragms are considered

- The diaphragm prestress is taken into account

- Axially symmetrical motions

- In-phase motion of the top and bottom diaphragms

As a result, a simple lumped model can be derived and presented by Eq.1-2 and the schematic representation in Fig. 2 and Fig. 3 .

$$
\begin{gathered}
m_{m f} \ddot{x}+d \dot{x}+(k+n) x+b x^{3}+\beta V_{\text {elec }}=m_{t f} \dot{V}_{\text {mec }} \\
\beta \dot{x}-C_{0} \dot{V}_{\text {elec }}=I
\end{gathered}
$$

Table II details the lumped parameters, their units and relationship to the geometry and material properties.

Table II: Model parameters relation

\begin{tabular}{lccc} 
Parameter & Symbol & Relation & Unit \\
\hline Fluid inertial mass & $m_{m f}$ & See $[11] f\left(\rho_{f}, H, R\right)$ & $\mathrm{kg}$ \\
Fluid excitation mass & $m_{t f}$ & $\frac{H \pi \rho_{f} R^{2}}{12}$ & $\mathrm{~kg}$ \\
Flexural stiffness & $k$ & $\frac{32 \pi E h^{3}}{9 R^{2}\left(1-v^{2}\right)}$ & $\mathrm{N} / \mathrm{m}$ \\
Tension stiffness & $b$ & $\frac{\pi E h\left(7505+4250 v-2791 v^{2}\right)}{39690 R^{2}\left(1-v^{2}\right)}$ & $\mathrm{N} / \mathrm{m}^{3}$ \\
Electromechanical coefficient & $\beta$ & $-\frac{64 \pi E d_{31} h}{9(1-v)}$ & $\mathrm{N} / \mathrm{V}$ \\
Diaphragm capacitance & $C_{0}$ & $\frac{2 \varepsilon_{33} \varepsilon_{0} \pi R^{2}}{3 h}$ & $\mathrm{~F}$ \\
Prestress flexural stiffness & $n^{*}$ & $\frac{4 u_{S 0} \pi E h}{3 R\left(1-v^{2}\right)}$ & $\mathrm{N} / \mathrm{m}$ \\
Damping coefficient & $d$ & $\frac{\sqrt{m_{m f}\left(k+n^{*}\right)}}{Q^{*}}$ & $\mathrm{~N} . \mathrm{s} / \mathrm{m}$ \\
\hline$*$ Measured values & & &
\end{tabular}

The mechanical model (Fig. 2) consists in a moving fluid mass $\left(m_{m f}\right)$ tied to a vertical spring $(k+n)$ standing for the flexural diaphragm stiffness and two springs $(b)$ standing for the stretching associated to large amplitude motions. The piezoelectric conversion $(\beta)$ is associated with the flexural stiffness. The diaphragm deformations induce a voltage between the diaphragm electrodes. The input force is $m_{t f} \dot{V}_{\text {mec }}$ with $\dot{V}_{\text {mec }}$ the frame acceleration. The damping coefficient (d) embodies all the mechanical losses (the losses within the membrane material and the fluid dissipation).

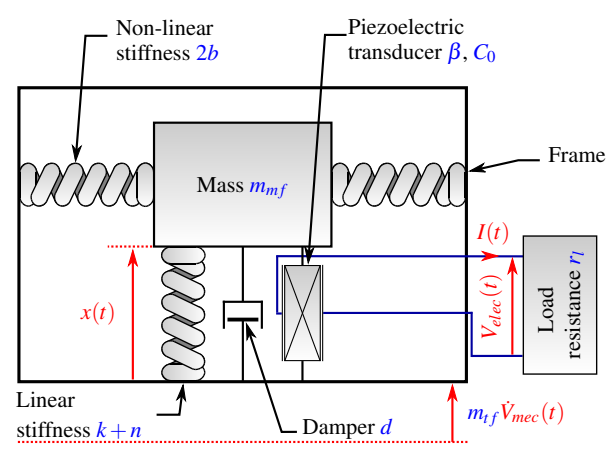

Figure 2: Mechanical model of linear inertial generator

The piezoelectric generator (Fig. 3) behaves as a voltage source whose value $\beta \dot{x}$ is parallel to a capacitance $\left(C_{0}\right)$ induced by the piezoelectric element. $V_{\text {elec }}$ is the electrical voltage across the load resistance.

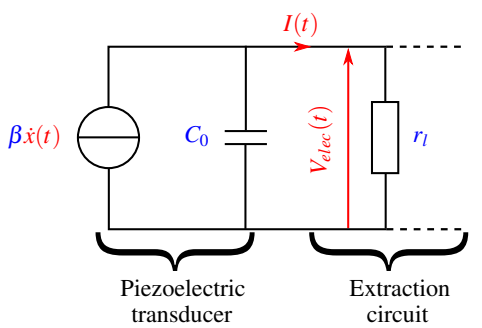

Figure 3: Linear inertial generator equivalent circuit

\section{Diaphragm solution}

In the case of small displacement, the nonlinear behavior effects are minor and the nonlinear stretching $(b)$ can be neglected. If a single layer (monomorph [12]) of electroactive material is used, during a flexural motion, the same amount of film is compressed and stretched across the thickness so the global generated voltage is zero (Fig. 4).

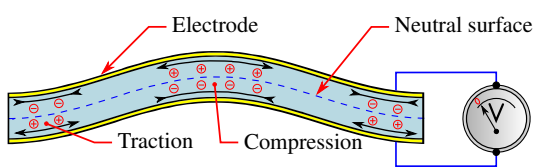

Figure 4: Flexural motion

To extract energy in linear behavior, a double layers (bimorph [12]) of electroactive polymer is to be used. This bimorph structure use complex electrodes geometry (Fig.5). So to extract energy, it is necessary to include an electrode on the neutral surface deformation splitting. Consequently, a 
membrane is composed of electro-active films with a common central electrode. The films are assembled with their polarity reversed. For differentiating the compression and the stretching on the radius, two areas have been delimitated, a disk and a ring. The model showed that the optimum radius of central electrode is $r_{1}=R \sqrt{1 / 3}$, and the inner radius of the external electrode is $r_{2}=R \sqrt{2 / 3}$. With these dimensions, the electrode surfaces are identical resulting in a same capacitance.

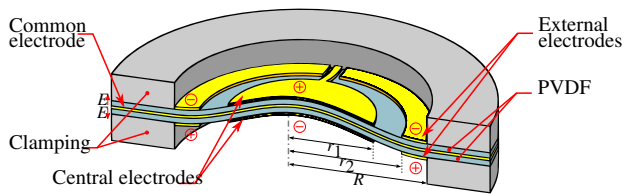

Figure 5: Bimorph diaphragm structure

\section{Prototype}

A HFD prototype has been realized aiming at the validation of the proposed model (Fig.6a). The geometrical and material properties of this prototype are presented in the table III. For this type of generator, the fluid used is glycerin and $\mathrm{P}(\mathrm{VDF}-\mathrm{TrFE})$ has been used for the membranes. This material is more flexible than a conventional PVDF and has similar piezoelectric properties. The Fig. $6 \mathrm{~b}$ shows the structure of the membranes made. To connect the generator to an extraction circuit, the connection areas were performed. But the surface electrode surface is larger than the ideal surface which increases the the film capacitor. It is this actual capacitance which is used for the simulations.

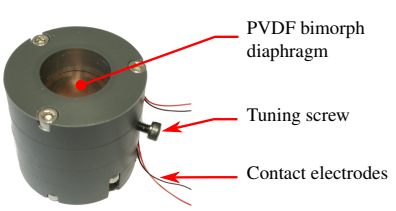

(a) Protoype

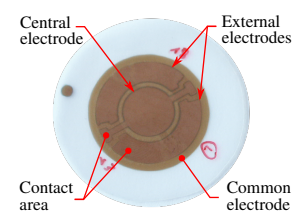

(b) Bimorphe diaphragm
Figure 6: Bimorph PHFD prototype

Table III: PHFD properties

\begin{tabular}{lc|cc}
\multicolumn{2}{c|}{ Geometrical properties } & \multicolumn{2}{|c}{ Material properties } \\
\hline$R$ & $10 \mathrm{~mm}$ & $E$ & $1 \mathrm{GPa}$ \\
$H$ & $40 \mathrm{~mm}$ & $\rho_{f}$ & $1260 \mathrm{~kg} / \mathrm{m}^{3}$ \\
$h$ & $125 \mu \mathrm{m}$ & $d_{31}$ & $-5 \mathrm{pC} / \mathrm{N}$ \\
\hline
\end{tabular}

The first step for the assembly procedure is the clamping of the cylinders to obtain two equal halves of the final PHFD. This operation is realized without fluid. When tightening, the membranes are stretched over a low shoulder to ensure flat surfaces producing mechanical prestress (coefficient $n$ in Eq.1). The next step is to put the two half-HFDs together immersed in a fluid to get a fluid-filled HFD without bubbles to ensure incompressibility. The tightness between the half-HFDs is assured by a o-ring. It is also possible to adjust the internal pressure, and consequently the flatness of the diaphragms, with a small tuning screw.

\section{E. Experimental setup}

The piezoelectric HFD was tested on an electro-dynamic shaker driven with a slow varying increasing frequency sweep from $100 \mathrm{~Hz}$ up to $250 \mathrm{~Hz}$. Using an accelerometer and a dedicated control unit, the shaker is driven using a closed-loop control to ensure constant acceleration amplitude throughout the frequency range. The displacement and the velocity of the top diaphragm center are measured using a differential laser vibrometer. In parallel, the control unit drives a set of electrical load resistances $\left(r_{l}\right)$. The generated power can be rigorously assessed varying the load between $0.1 \mathrm{M} \Omega$ and $12 \mathrm{M} \Omega$.

\section{THEORETICAL AND EXPERIMENTAL RESULTS}

\section{A. Model validation}

Experiment using frequency sweep at $10 \mathrm{~m} / \mathrm{s}^{2}$ constant acceleration and various load resistances have been performed and the results (red grid in Fig. 7 and Fig. 8 ) are compared to simulation results (color scale). Fig. 7 shows the displacements with respect to the excitation frequencies and load resistances. The first resonant frequency of the system is $164.37 \mathrm{~Hz}$. The displacement amplitude at resonant frequency is $71.45 \mu \mathrm{m}$. The electric conversion has a negligible impact on the displacement, reflecting a weak electromechanical coupling. The simulations show a good correlation with the experimental results for the mechanical behavior.

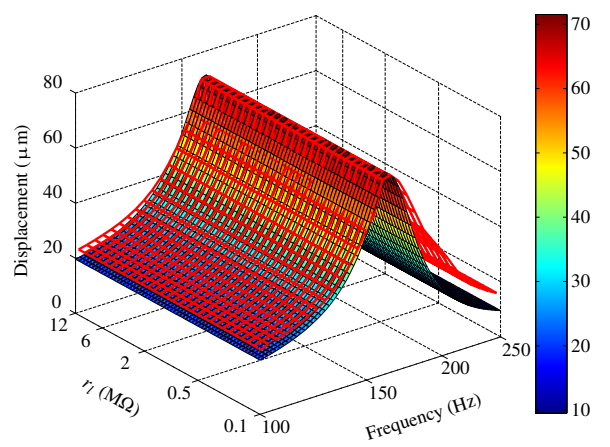

Figure 7: Displacement comparison

Fig. 8 shows the power of one layer of one diaphragm. The results show a bad correlation on the electric behavior. The simulation (color scale) overestimates the maximal power $\left(P_{\text {max } t h}=929.02 \mathrm{nW}\right)$ as well as the load resistance $\left(R_{\text {opti } t h}=\right.$ $7.99 \mathrm{M} \Omega$ ). The experimental power (red grid) is $P_{\text {max_exp }}=$ $60.41 \mathrm{nW}$ for a load resistance of $R_{\text {opti_exp }}=1.34 \mathrm{M} \Omega$. However, the mechanical damping effect allows to have a high bandwidth of $53.48 \mathrm{~Hz}$. This important gap between results allowed to highlight a problem on the film realization. Indeed, a low resistance in parallel of the film capacitance decrease strongly the HFD performance.

The confrontation between the experimental results and the model prediction showed a parasitic resistance in the circuit. Considering the parallel resistance is composed of a single 




Figure 8: Power comparison

resistance, $r_{p}$ value can be estimated using the inverse of the difference between $R_{\text {opti_exp }}{ }^{-1}$ and $R_{\text {opti_th }}{ }^{-1}$. The theoretical value of the parasitic resistance of $r_{p}$ is $1.58 \mathrm{M} \Omega$. The origin of $r_{p}$ remains to be determined and validated.

\section{B. Consideration of the parasitic resistance}

Taking into account the parasitic resistance, the electrical behavior can be presented by Eq. 3 and the schematic representation in Fig. 9.

$$
\beta \dot{x}-C_{0} \dot{V}_{\text {elec }}-\frac{V_{\text {elec }}}{r_{p}}=I
$$

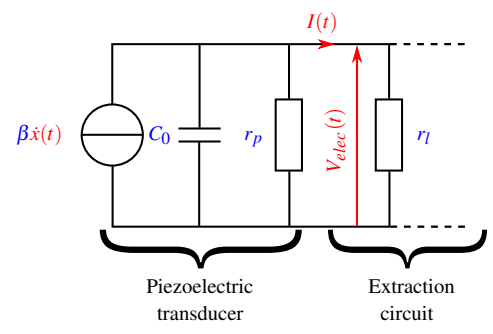

Figure 9: Modified electrical model of linear inertial generator

The piezoelectric transducer is represented by a voltage source in parallel of the capacitance $\left(C_{0}\right)$ and the parasitic resistance $\left(r_{p}\right)$. The extraction circuit is represented by a load resistance $\left(r_{l}\right)$. The new modeling results incorporating $r_{p}$ effect are presented Fig. 10.

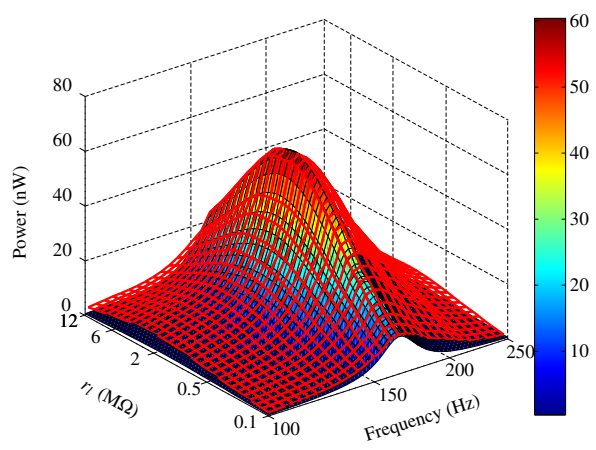

Figure 10: Bimorph HFD comparison

The comparison between the experimental results and the simulation shows a good agreement. The resonant frequency and the optimal load resistance match perfectly. The simulated bandwidth is $29.31 \mathrm{~Hz}$ which is underestimated compared to the experimental bandwidth.

\section{CONCLUSION}

An original membrane generator matching low frequency vibration energy harvesting applications is proposed. A complete theoretical model has been developed. A prototype was realized and is thoroughly investigated aiming at the validation of the theoretical model. In this first prototype, custom $\mathrm{P}(\mathrm{VDF}-\mathrm{TrFE})$ film is used. The experimental results show an unexpected parasitic resistance induced by the metallization protocol. This resistance is then added to complete the model. In th evicinity of the maximum power peak with respect to the excitation frequency and the electrical load resistance, the model gives good predictive results. The realized generator exhibits low resonant frequency of $164.37 \mathrm{~Hz}$ for low acceleration $\left(10 \mathrm{~m} / \mathrm{s}^{2}\right)$ and power density of $3.04 \mu \mathrm{W} / \mathrm{cm}^{3}$. Future approaches plan to improve the assembly procedure in order to increase the generated power and expect the theoretical power density of $78.98 \mu \mathrm{W} / \mathrm{cm}^{3}$.

\section{ACKNOWLEDGMENT}

This work was supported by the CEntre Technique des Industries Mécaniques (CETIM) and the Assemblée des Pays de Savoie (APS). The authors gratefully acknowledge this support and the help of the LGEF laboratory of INSA de Lyon.

\section{REFERENCES}

[1] J. A. Paradiso, "Energy scavenging for mobile and wireless electronics," IEEE Pervasive Comput, vol. 4, no. 1, pp. 18-27, 2005.

[2] S. P. Beeby, M. J. Tudor, and N. M. White, "Energy harvesting vibration sources for microsystems applications," Meas. Sci. Technol., vol. 17, no. 12, pp. R175-R195, Dec. 2006.

[3] P. D. Mitcheson, E. M. Yeatman, G. K. Rao, A. S. Holmes, and T. C. Green, "Human and Machine Motion for Wireless Electronic Devices," Proc. IEEE, vol. 96, no. 9, pp. 1457-1486, 2008.

[4] S. Roundy, P. K. Wright, and J. Rabaey, "A study of low level vibrations as a power source for wireless sensor nodes," Comput. Commun.,, vol. 26, no. 11, pp. 1131-1144, 2003.

[5] S. Rammohan, C. Ramya, and S. Jayanth Kumar, "Low Frequency Vibration Energy Harvesting using Arrays of PVDF Piezoelectric Bimorphs ," J. Inst. smart Struct. ans Syst., vol. 3, no. 1, pp. 18-27, 2014

[6] M. Kato and K.-i. Kakimoto, "Processing and energy-harvesting ability of ( $\mathrm{Na}, \mathrm{K}$ ) $\mathrm{NbO} 3$ particle-dispersed fi brous polyvinylidene fl uoride multilayer composite," Mater. Lett., vol. 156, pp. 183-186, 2015.

[7] Y. Jiang, S. Shiono, and H. Hamada, "Low-frequency energy harvesting using a laminated PVDF cantilever with a magnetic mass," Proc. PowerMEMS 2010, p. 375, 2010

[8] R. Lockhart, R. Dauksevicius, a. V. Quintero, P. Janphuang, D. Briand, and N. F. de Rooij, "Flexible and Robust Multilayer Micro-Vibrational Harvesters for High Acceleration Environments," J. Phys. Conf. Ser. vol. 476, p. 012113, 2013.

[9] X.-r. Chen, T.-q. Yang, W. Wang, and X. Yao, "Vibration energy harvesting with a clamped piezoelectric circular diaphragm," Ceram. Int., vol. 38, pp. S271-S274, Jan. 2012.

[10] C. Mo, L. J. Radziemski, and W. W. Clark, "Experimental validation of energy harvesting performance for pressure-loaded piezoelectric circular diaphragms," Smart Mater. Struct., vol. 19, no. 7, p. 075010, Jul. 2010.

[11] F. Formosa, A. Badel, and H. Favrelière, "Development of low frequency, insulating thick diaphragms for power MEMS applications," Sensors Actuators A Phys., vol. 189, pp. 370-379, Jan. 2013.

[12] T. Li, Y. Chen, F. Boey, and J. Ma, "Domain reorientation of piezoelectric bending actuators," Sensors Actuators A Phys., vol. 134, no. 2, pp. 544-554, Mar. 2007. 